\title{
Combination of soya protein and polydextrose reduces energy intake and glycaemic response via modulation of gastric emptying rate, ghrelin and glucagon-like peptide-1 in Chinese
}

\author{
Yean Yean Soong ${ }^{1,2}$, Wen Xin Lim $^{1,2}$, Melvin Khee Shing Leow ${ }^{1,2,3}$, Phei Ching Siow ${ }^{1,2}$, Ai Ling Teh ${ }^{2}$ and \\ Christiani Jeyakumar Henry ${ }^{1,2,4 *}$ \\ ${ }^{1}$ Clinical Nutrition Research Centre (CNRC), Singapore Institute for Clinical Sciences, 14 Medical Drive, \#07-02, Singapore \\ 117599, Singapore \\ ${ }^{2}$ Singapore Institute for Clinical Sciences, Agency for Science, Technology and Research (A*STAR), 30 Medical Drive, Singapore \\ 117609 , Singapore \\ ${ }^{3}$ Department of Endocrinology, Tan Tock Seng Hospital, 11 Jalan Tan Tock Seng, Singapore 308433, Singapore \\ ${ }^{4}$ Department of Biochemistry, National University of Singapore, 8 Medical Drive, Singapore 117596, Singapore \\ (Submitted 15 February 2016 - Accepted 24 March 2016)
}

\section{Abstract}

The short-term effect of soya protein, polydextrose and their combination on energy intake (EI) was investigated in Chinese. In total, twentyseven healthy, normotensive and lean Chinese men aged 21-40 years were given four different soyabean curd preloads with or without polydextrose. The study was a repeated-measure, randomised, cross-over design. The consumption of high-protein soyabean curd alone or in addition with polydextrose as a preload led to greater reduction in EI at a subsequent meal. A similar observation was also found after intake of low-protein soyabean curd with polydextrose. The gut hormone responses mirrored the reduction in food intake. It appears that incorporation of polydextrose either with low- or high-protein soyabean curd could be a potential strategy to reduce EI and assist with weight management. The popular consumption of soyabean curd in Chinese makes it an ideal vehicle for incorporation of polydextrose. This evidence-based dietary approach can serve as a guideline for developing functional foods for weight reduction and weight maintenance.

\section{Key words: Soyabean curd: Polydextrose: Food intake: Gut hormones: Gastric emptying}

Soyabean curd is a popular and widely consumed dessert among Chinese in most regions of Asia. It is frequently served at breakfast and teatime. Traditional foods made from soyabean, including bean curd (tofu), miso, natto, shoyu and tempeh have been consumed for centuries. Soyabean contains approximately $35-40 \%$ protein. It is an important plant source of dietary protein for Asians. Storage proteins, conglycinin and glycinin are the predominant proteins comprising approximately $80 \%$ of the total proteins in soyabean ${ }^{(1)}$. The essential amino acid content makes soya protein comparable in protein quality with milk, meat, fish and eggs ${ }^{(2)}$. Protein is known to be satiating and different protein sources are speculated to differ in their satiating capacity ${ }^{(3,4)}$. Soya protein has also been shown to suppress food intake by increasing satiety ${ }^{(5)}$. Soyabean curd has the consistency of thick yogurt and is made from soyamilk.

Polydextrose is a randomly bonded glucose polymer with an average molecular weight of $2 \mathrm{kDa}$ and a degree of polymerisation of approximately 12 glucose units ${ }^{(6)}$. The atypical glycosidic linkages produced in the highly branched structure prevent the hydrolysis of polydextrose by human digestive enzymes. It is minimally absorbed in the small intestine and about $50 \%$ is fermented in the large intestine yielding approximately $4.184 \mathrm{~kJ} / \mathrm{g}$ $(1 \mathrm{kcal} / \mathrm{g})$ through bacterial fermentation and SCFA production ${ }^{(6)}$. Polydextrose also elicits a lower postprandial glycaemic response (GR) compared with glucose ${ }^{(7)}$. Recent studies have demonstrated a significant reduction in energy intake (EI) after consuming smoothie and yogurt containing polydextrose when compared with controls ${ }^{(8-10)}$. Yet, polydextrose added to muffins and sweetened lemon-flavoured beverage did not show an effect on satiety ${ }^{(11,12)}$. This suggests that the mechanism of action of polydextrose is dependent on whether the food is liquid (including viscosity) or solid. Thus, the nature of delivery of polydextrose in various food vehicles may have differing metabolic outcomes.

Considering the reported satiety effect of soya protein and polydextrose, inclusion of these food ingredients in the diet

Abbreviations: EI, energy intake; GER, gastric emptying rate; GLP-1, plasma glucagon-like peptide-1; GR, glycaemic response; HP, high protein; HPP, high protein with polydextrose; IAUC, incremental AUC; LP, low protein; LPP, low protein with polydextrose; VAS, visual analogue scales

*Corresponding author: Professor C. J. Henry, fax +656774 7134, email jeya_henry@sics.a-star.edu.sg 
could potentially reduce the short-term EI. Given the widespread use of soyabean curd among Chinese, the novelty of our study was to determine whether the combination of soya with polydextrose could be used as a dietary intervention to modulate EI. As far as we are aware, no other study has examined the potential additive effect of soya and polydextrose on regulating EI. Second, very few studies have been carried out on Asians and their metabolic responses to diets appear to be markedly different to that in Europeans ${ }^{(13)}$. It was therefore necessary to determine whether polydextrose intake among Chinese produced similar observations as reported in Europeans. Our study therefore had two parts: (1) to determine whether a dose-response effect of soya protein on EI existed and (2) to determine whether a synergistic effect of soya protein and polydextrose existed on ad libitum EI. In addition, appetite ratings and physiological responses including gastric emptying, fasting and postprandial glucose, plasma insulin, ghrelin and glucagon-like peptide-1 (GLP-1) were examined in our subjects. This is the first study to examine the ad libitum EI, appetite and metabolic responses to soya protein and polydextrose in Chinese.

\section{Methods}

\section{Subjects}

The study was conducted at the Clinical Nutrition Research Centre, Agency for Science, Technology and Research, Singapore. In total, twenty-seven healthy normotensive Chinese men aged 21-40 years with a BMI between 18 and $24 \mathrm{~kg} / \mathrm{m}^{2}$ and fasting blood glucose levels $<6.0 \mathrm{mmol} / \mathrm{l}$ were recruited. Table 1 shows their baseline characteristics. Physical activity level was quantified using the questionnaire of Baecke et al. ${ }^{(14)}$. Preceding each test day, the subjects were instructed to avoid alcohol and caffeinated beverages or strenuous exercise (defined as activity exceeding 6 metabolic equivalents (METs)) such as running, cycling, playing soccer, etc. Alcohol- and caffeine-containing beverages and intense physical activity were restricted the evening preceding a test day. Subjects with food hypersensitivity, on prescription medication or partaking competitive sports were excluded. All subjects gave their written informed consent. The purpose of the present study was clearly disclosed via standard informed consent procedure. The subjects were not informed about the composition of the

Table 1. Subject characteristics at baseline (Mean values with their standard errors; $n$ 27)

\begin{tabular}{lrc}
\hline & Mean & SE \\
\hline Age (years) & 23.6 & 0.6 \\
Height $(\mathrm{m})$ & 1.7 & 0.0 \\
Weight $(\mathrm{kg})$ & 62.1 & 1.2 \\
BMl $\left(\mathrm{kg} / \mathrm{m}^{2}\right)$ & 21.1 & 0.4 \\
Waist:hip ratio & 0.8 & 0.0 \\
Fasting plasma glucose (mmol/l) & 4.5 & 0.1 \\
DEBQ $^{*}$ & 1.9 & 0.1 \\
\hline
\end{tabular}

DEBQ, Dutch Eating Behaviour Questionnaire.

* Score on the restrained-eating scale of the DEBQ. The range of possible score: $1 \cdot 0-5 \cdot 0$. preload provided at each session. This study was conducted according to the guidelines laid down in the Declaration of Helsinki and was approved by our local Institutional Review Board (DSRB C 2013/00383).

\section{Study design}

Each subject received four soyabean curd preloads on separate days with a washout period of at least $5 \mathrm{~d}$ between the preloads according to a repeated-measures, randomised, cross-over design. Subjects were randomised using 'Research Randomizer' (http://www.randomizer.org). Standardised, microwavable ready-meals were provided for dinner on the night preceding each test day. After a 10-h overnight fast, subjects arrived at the centre between 08.00 and 08.30 hours to consume their breakfast. Subjects were allowed to consume water (up to $250 \mathrm{ml}$ ) between breakfast and $30 \mathrm{~min}$ before preload consumption. Preload was served $3 \mathrm{~h}$ post-breakfast and consumed in $<15 \mathrm{~min}$. At baseline (before preload consumption) and at 15, 30, 45, 60, 75 and $90 \mathrm{~min}$ after preload consumption, finger-prick capillary blood glucose test, abdominal ultrasound for gastric emptying rate (GER) and assessment of subjective feelings via visual analogue scales (VAS) of hunger, fullness, desire to eat and prospective food consumption were performed. In a subgroup of fifteen subjects, the antecubital vein of each subject's forearm was cannulated $1 \mathrm{~h}$ before the preload and was kept patent with saline $(0 \cdot 9 \% \mathrm{NaCl})$ for serial blood sampling to measure insulin, ghrelin and GLP-1. These subjects were randomly selected out of twenty-seven subjects. There was no statistical difference $(P>0.05)$ in baseline characteristics between the fifteen and twelve subjects. Buffetstyle ad libitum lunch was served in a climate-controlled dining room (ambient temperature: $22 \pm 1^{\circ} \mathrm{C}$ ). To minimise the effects of social interactions on food intake, subjects ate alone until comfortably full. Lunch intake (evaluated after each subject finished and left) was only revealed after the study to avoid biasing the quantity eaten if this was made known at the outset. The food refusals were weighed and the energy and nutrient contents were calculated using the nutrition information panel provided by the manufacturers.

\section{Study meals}

Standardised dinner consisted of three meal plans (CP Ready Meals (Singapore), e.g. teriyaki chicken with rice, chicken green curry with rice, shrimp wanton with egg noodles) of choice matched to provide $3 \mathrm{MJ}$ and 11, 75 and $14 \%$ of energy as protein, carbohydrate and fat, respectively. Subjects consumed the chosen standardised dinner meal plan throughout the study. The subjects were advised to consume the meal in its entirety. When the subjects arrived for the test session, we confirmed with the subjects whether they ate the meal and they replied affirmatively. All subjects ate the same standardised meal that contained equal amount of energy and macronutrients. The standardised breakfast that was fully consumed provided $1 \mathrm{MJ}$ and 9,82 and 9\% of energy as protein, carbohydrate and fat, respectively. The soyabean curd preloads were prepared using standard methodology ${ }^{(15)}$, with soyabean milk freshly boiled from organic soyabean (Origins Healthfood), soya protein isolate (True Nutrition), Litesse ${ }^{\circledR}$ ultra powder polydextrose 
Table 2. Macronutrient composition of the four soyabean curd preloads

\begin{tabular}{lcccc}
\hline & LP & LPP & HP & HPP \\
\hline Amount $(\mathrm{g})$ & 450.9 & 462.8 & 461.28 & 473.13 \\
Carbohydrate $(\mathrm{g})^{*}$ & 44.0 & 44.3 & 46.3 & 46.6 \\
Fat $(\mathrm{g})^{*}$ & 16.0 & 16.0 & 8.5 & 8.3 \\
Protein $(\mathrm{g})^{*}$ & 15.8 & 15.8 & 30.8 & 30.8 \\
Polydextrose $(\mathrm{g})$ & - & 12.0 & - & 12.0 \\
Energy (MJ) & 1.6 & 1.6 & 1.6 & 1.6 \\
\hline
\end{tabular}

LP, low protein; LPP, low protein with polydextrose; HP, high protein; HPP, high protein with polydextrose.

* Carbohydrate, fat and protein contents were chemically analysed. The fibre content was calculated from the manufacturer's product data sheet.

(DuPont), glucono delta-lactone (Redman), Grindsted ${ }^{\circledR}$ SSL P 70 VEG emulsifier sodium stearoyl lactylate (DuPont), white sugar (SIS) and soyabean oil (NTUC). The total amount served provided $1.6 \mathrm{MJ}$, consisting of 16,46 and $38 \%$ of energy as protein, carbohydrate and fat for low-protein (LP) and low-protein with polydextrose (LPP) preloads and 32, 48 and 20\% of energy as protein, carbohydrate and fat for high-protein (HP) and highprotein with polydextrose (HPP) preloads, respectively. Energy, $\mathrm{pH}$, volume and palatability of soyabean curds were closely matched. The composition of the preloads is presented in Table 2.

Ad libitum lunch and table water $(1500 \mathrm{ml})$ served provided $17 \cdot 32 \mathrm{MJ}$, consisting of 11,64 , and $25 \%$ of energy as protein, carbohydrate and fat, respectively. The mean energy density of the lunches was $0.45 \mathrm{MJ} / 100 \mathrm{~g}$ wet weight of food. Energy and nutrient compositions were calculated using the manufacturer's product data sheet and McCance and Widdowson's The Composition of Foods integrated data set.

\section{Subjective satiety}

Subjective motivational ratings for hunger, fullness, desire to eat and prospective food consumption were measured by VAS before breakfast and 1 and $2 \mathrm{~h}$ after breakfast, before preload, 15, 30, 45, 60 and $75 \mathrm{~min}$ after the preload, and before and after lunch. Appetite profiles were expressed as absolute changes ( $\mathrm{mm}$ VAS) from the basal values (0 min).

\section{Ultrasonographic examination technique}

The sonographic examination was performed by adapting the methods of Darwiche et al. ${ }^{(16)}$. Real-time ultrasonography is a valid method for estimating GER. Good correlation was also found between the ultrasonographic and the scintigraphic method $^{(17,18)}$. GE LOGIQ P5 digital colour Doppler scanners system (GE Healthcare) with a $4 \mathrm{C} 5 \mathrm{MHz}$ convex transducer probe was used to monitor gastric emptying. Triplicate measurements of the longitudinal (D1) and antero-posterior (D2) diameters of a single section of the gastric antrum were performed by a single operator at each time point using the abdominal aorta and the left lobe of the liver as internal landmarks. The mean values of longitudinal (D1 mean) and antero-posterior (D2 mean) diameters were used to calculate the antral cross-sectional area $\left(A_{\text {Antrum }}\right)$ based on the following formula:

$$
A_{\text {Antrum }}=(\pi \times \mathrm{D} 1 \text { mean } \times \mathrm{D} 2 \text { mean }) / 4 \text {. }
$$

GER was estimated and expressed as the percentage reduction in antral cross-sectional area from 15 to $90 \mathrm{~min}$, calculated as follows:

$$
\mathrm{GER}=\left(\left(A_{\text {area }} 90 \mathrm{~min} / A_{\text {area }} 15 \mathrm{~min}\right)-1\right) \times 100 .
$$

\section{Biochemical analyses}

Blood samples obtained by the finger-prick test using the Accu-Chek Safe-T-Pro Plus ${ }^{\circledR}$ single-use lancing device (Roche Diagnostics Asia Pacific) were used to measure capillary blood glucose on the calibrated HemoCue Glucose 201+analysers (HemoCue ${ }^{\circledR}$ Ltd). Venous blood samples were collected into BD Vacutainer ${ }^{\circledR}$ Plus Plastic $\mathrm{K}_{2}$ EDTA tubes (Becton, Dickinson and Company) for plasma insulin analysis. BD ${ }^{\mathrm{TM}}$ Plus Plastic P800 tubes (Becton, Dickinson and Company) containing dipeptidyl peptidase-4, esterase and other protease inhibitors were used to collect venous blood samples for plasma total ghrelin and active GLP-1 analysis. Blood samples were stored on ice, and the plasma was separated within 15 min of collection by centrifugation $\left(10 \mathrm{~min}, 1000 \mathrm{~g}, 4^{\circ} \mathrm{C}\right.$ ) (Sorvall ${ }^{\mathrm{TM}} \mathrm{ST} 16$ Centrifuge; Thermo Fisher Scientific Inc.). The plasma was stored in microcentrifuge tubes at $-80^{\circ} \mathrm{C}$ until analysis. Plasma insulin ( $1.9 \%$ intra-assay CV; $2.6 \%$ inter-assay CV) was determined on the immunoassay analyser Cobas e 411 (Roche Diagnostics $\mathrm{GmbH}$ ). Commercially available ELISA kits (Merck Millipore) were used to measure total ghrelin (1.8\% intra-assay $\mathrm{CV} ; 7.7 \%$ inter-assay CV) and active GLP-1 (6.7\% intra-assay CV; $6 \cdot 1 \%$ inter-assay CV).

\section{Statistical analyses}

The incremental AUC (IAUC) or area above the curve (AAC) was calculated using the trapezoidal rule, subtracting the baseline values over $90 \mathrm{~min}$ from the total IAUC/AAC. Analysis for repeated measurements followed by a Bonferroni post hoc test was applied to examine differences between the soyabean curd preloads for changes in VAS ratings (hunger, fullness, desire to eat and prospective food consumption), EI, GER, glucose, insulin, GLP-1 and ghrelin. Statistical analyses were conducted using SPSS software (SPSS Inc.), version 23.0. Descriptive statistics are presented as mean values with their standard errors, unless otherwise indicated. All $P$ values were two-sided, and $P<0.05$ was considered to be statistically significant.

\section{Results}

\section{Energy and macronutrient intakes}

EI at lunch was significantly lower following the consumption of LPP, HP and HPP preloads compared with the LP preload $(P<0.05)$ (Table 3). There were no significant differences in EI between LPP, HP and HPP. Consumption of LPP, HP and HPP preloads resulted in an energy reduction of approximately $394 \mathrm{~kJ}(11 \%), 445 \mathrm{~kJ}(12 \%)$ and $463 \mathrm{~kJ}$ (13\%), respectively, compared with the LP preload. The carbohydrate intake at lunch after consuming HP and HPP preloads (109.3 and $112 \cdot 1 \mathrm{~g}$ of carbohydrate, respectively) was significantly lower than after the LP preload $(126 \cdot 1 \mathrm{~g})(P<0 \cdot 01)$. A significant reduction in fat 
Table 3. Nutrient and energy intakes at lunch (Mean values with their standard errors)

\begin{tabular}{|c|c|c|c|c|c|c|c|c|}
\hline & \multicolumn{2}{|c|}{ LP } & \multicolumn{2}{|c|}{ LPP } & \multicolumn{2}{|c|}{$\mathrm{HP}$} & \multicolumn{2}{|c|}{ HPP } \\
\hline & Mean & SE & Mean & SE & Mean & SE & Mean & SE \\
\hline Energy (kJ) & $3702 \cdot 49^{a}$ & $176 \cdot 25$ & $3308.33^{b}$ & 186.59 & $3256.57^{b}$ & $203 \cdot 21$ & $3239 \cdot 30^{\mathrm{b}}$ & 195.55 \\
\hline Protein (g) & 29.25 & 1.95 & 26.58 & 1.86 & $26 \cdot 24$ & 2.03 & $25 \cdot 20$ & 1.95 \\
\hline Carbohydrate (g) & $126 \cdot 15^{c}$ & 5.93 & $112 \cdot 11$ & $6 \cdot 72$ & $109 \cdot 32^{d}$ & 6.99 & $112 \cdot 11^{d}$ & 7.29 \\
\hline Fat $(\mathrm{g})$ & $29.75^{e}$ & 1.65 & 26.66 & 1.67 & $26 \cdot 61$ & 1.84 & $25 \cdot 52^{f}$ & 1.61 \\
\hline
\end{tabular}

LP, low protein; LPP, low protein with polydextrose; HP, high protein; HPP, high protein with polydextrose.

$\mathrm{a}, \mathrm{b}, \mathrm{c}, \mathrm{d}, \mathrm{e}, \mathrm{f}$ Mean values within a row with unlike superscript letters were significantly different $(P<0.05)$.

Table 4. Incremental AUC/area above the curve for subjective feelings*

(Mean values with their standard errors)

\begin{tabular}{|c|c|c|c|c|c|c|c|c|}
\hline & \multicolumn{2}{|c|}{ LP } & \multicolumn{2}{|c|}{ LPP } & \multicolumn{2}{|c|}{$\mathrm{HP}$} & \multicolumn{2}{|c|}{ HPP } \\
\hline & Mean & $\mathrm{SE}$ & Mean & SE & Mean & SE & Mean & SE \\
\hline Feeling of hunger $(\min \times \mathrm{mm})$ & $1891 \cdot 37$ & $261 \cdot 23$ & $1852 \cdot 47$ & 354.95 & 1953.69 & $304 \cdot 19$ & $1738 \cdot 41$ & 274.94 \\
\hline Feeling of fullness $(\mathrm{min} \times \mathrm{mm})$ & $1961 \cdot 71$ & 274.46 & 1892.44 & $302 \cdot 21$ & $2189 \cdot 76$ & $285 \cdot 66$ & $1809 \cdot 11$ & 269.91 \\
\hline Feeling of desire to eat $(\min \times \mathrm{mm})$ & 1855.67 & 243.93 & 1885.88 & 243.93 & $1882 \cdot 31$ & $321 \cdot 19$ & 1926.62 & 259.40 \\
\hline Feeling of prospective food consumption ( $\min \times \mathrm{mm})$ & $1581 \cdot 10$ & $267 \cdot 64$ & $1405 \cdot 25$ & 283.34 & $1768 \cdot 25$ & 293.91 & 1508.54 & 245.83 \\
\hline
\end{tabular}

LP, low protein; LPP, low protein with polydextrose; HP, high protein; HPP, high protein with polydextrose.

* The incremental AUC/area above the curve represent the time between consuming the soyabean curd and the initiation of lunch. None of the subjective sensations was significantly different between the test meals $(P>0.05)$.

intake was observed following the consumption of the HPP preload compared with the LP preload $(25.5 \mathrm{v} .29 .7 \mathrm{~g}$ fat, respectively) $(P<0.05)$. The protein intake did not differ significantly after consuming the four preloads. The macronutrients were consumed in greater amounts in the LP preload treatment compared with the LPP, HP and HPP preloads treatment.

\section{Subjective motivational ratings}

The temporal changes in the subjective ratings for hunger, fullness, desire to eat, palatability of the preloads and prospective food consumption were comparable for the LP, LPP, HP and HPP preloads. The greatest satiety was observed $15 \mathrm{~min}$ after consuming the preloads, thereafter satiety decreased progressively. The VAS IAUC from before consuming preload until the initiation of lunch was not significantly different (Table 4). The four preloads produced similar degrees of subjective hunger, fullness, desire to eat and prospective food consumption sensations. None of the subjects reported any discomfort after consumption of the preload. It has been reported that discomfort only occurs after excessive consumption of polydextrose ${ }^{(19)}$. Consumption of reasonably modest $12 \mathrm{~g}$ of polydextrose in this study did not lead to bloating, given that we did not exceed the laxative threshold of polydextrose of $50 \mathrm{~g}$ as a single dose. In addition, there were no differences in palatability between preloads with and without polydextrose in both low- and high-dose protein groups $(P<0 \cdot 05)$.

\section{Gastric emptying}

The average baseline value of the gastric antral cross-sectional area before the consumption of preloads was 312.92 (SE 10.88) $\mathrm{mm}^{2}$. At 15 min after LP, LPP, HP and HPP preloads, the average antral cross-sectional areas were 1135.95 (sE 49.39), 1102.12 (sE 64.97), 1072.28 (sE 42.33) and 1165.09 (SE 42.67) $\mathrm{mm}^{2}$, respectively. The most distended antral cross-sectional area was observed $15 \mathrm{~min}$ after consumption of the preloads. Thereafter, it decreased progressively (Fig. 1(A)). At 45-90 min, HPP had a higher antral cross-sectional area compared with LP $(P<0.05)$. Greater antral cross-sectional area was also observed after consuming the HP preload compared with the LP preload at $90 \mathrm{~min} \quad(P<0.01)$. At $90 \mathrm{~min}$, the average values of the antral cross-sectional areas after LP, LPP, HP and HPP preloads consumption were 654.71 (SE 43.14), 799.04 (SE 54.56), 835.95 (SE 36.16) and 926.38 (SE 35.70) $\mathrm{mm}^{2}$, respectively. A significant, slower GER was observed after LPP (26\%), HP (20\%) and HPP (18\%) preloads consumption compared with the LP preload (40\%) $(P<0.05)$ (Fig. 1(B)).

\section{Glucose and insulin responses}

The temporal patterns were distinct for GR following the consumption of LP, LPP, HP and HPP preloads but comparable for insulinaemic response (IR) (Table 5). The incremental blood glucose and plasma insulin values during the $90 \mathrm{~min}$ after the consumption of preloads are shown in Fig. 2(A) and (B). Following consumption of LP, LPP, HP and HPP preloads, the peak GR and IR occurred at $30 \mathrm{~min}$. At $15 \mathrm{~min}$, both HP and HPP had lower glucose concentrations compared with LP $(P<0.05)$. No difference was observed between HP and HPP. At 45-75 min, HP had lower glucose concentration compared with LP $(P<0.05)$. This resulted in a lower and sustained GR of HP preload treatment, eliciting a significantly lower GR IAUC compared with both LP and LPP preload treatments $(P<0.05)$. The consumption of HPP preload gave rise to a non-significant reduction in GR IAUC compared with the LP preload treatment $(P=0 \cdot 054)$. There was no significant difference with respect to 
(A)

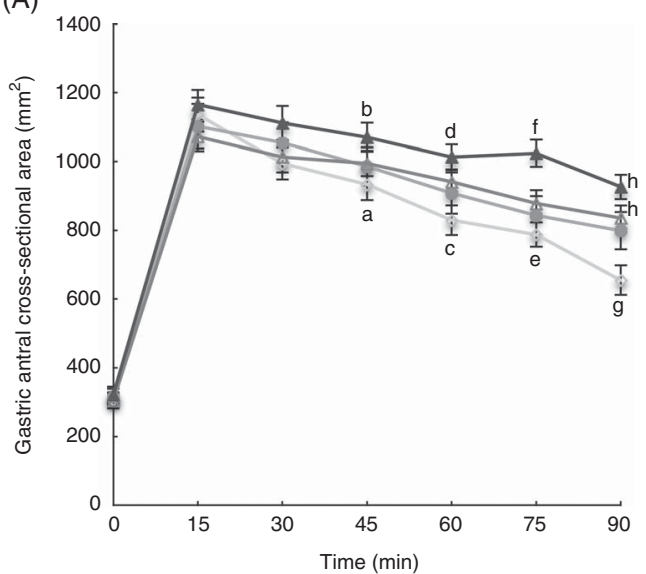

(B)

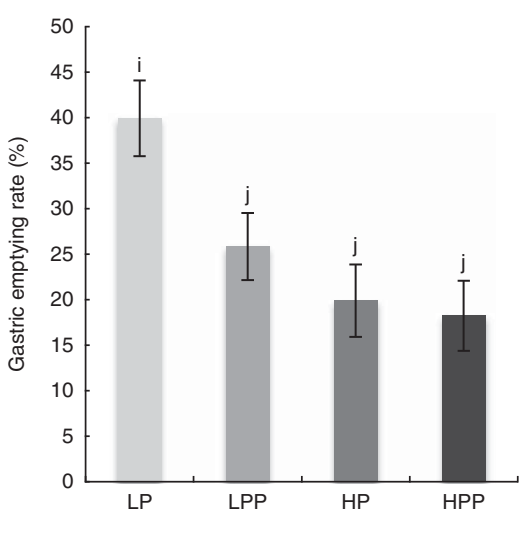

Fig. 1. (A) The gastric antral cross-sectional area across different time points and (B) gastric emptying rate after consumption of soya protein and polydextrose preloads. Values are means, with their standard errors represented by vertical bars. ${ }^{a, b, c, d, e, f, g, h}$ Mean values at the same time point with unlike superscript letters were significantly different $(P<0.05)$. ${ }^{\mathrm{i}, \mathrm{j}}$ Mean values with unlike superscript letters were significantly different $(P<0.05)$. $\smile$, Low protein $(\mathrm{LP})$; -- , low protein with polydextrose (LPP); $\triangle$, high protein (HP); - , high protein with polydextrose (HPP).

Table 5. Incremental AUC of glucose $(\mathrm{mmol} \times \mathrm{min} / \mathrm{l})$, insulin $(\mu \mathrm{U} \times \mathrm{min} / \mathrm{l})$, glucagon-like peptide-1 $(\mathrm{GLP}-1)(\mathrm{pmol} \times \mathrm{min} / \mathrm{l})$ and area above the curve of ghrelin $(\mathrm{pg} \times \mathrm{min} / \mathrm{ml})$ responses after consumption of soya protein and polydextrose preloads (Mean values with their standard errors)

\begin{tabular}{|c|c|c|c|c|c|c|c|c|}
\hline & \multicolumn{2}{|c|}{ LP } & \multicolumn{2}{|c|}{ LPP } & \multicolumn{2}{|c|}{$\mathrm{HP}$} & \multicolumn{2}{|c|}{ HPP } \\
\hline & Mean & SE & Mean & SE & Mean & SE & Mean & SE \\
\hline Glucose ( $n$ 27) & $108 \cdot 68^{a}$ & 8.40 & $102 \cdot 71^{a}$ & $7 \cdot 85$ & $78 \cdot 18^{b}$ & 7.14 & 87.66 & 7.05 \\
\hline Insulin (n 27) & $1531 \cdot 13$ & $164 \cdot 33$ & $1534 \cdot 72$ & $146 \cdot 42$ & $1569 \cdot 54$ & 154.69 & 1537.4 & $140 \cdot 00$ \\
\hline GLP-1 ( $n$ 15) & $262 \cdot 87$ & $87 \cdot 76$ & $338.97^{c}$ & $125 \cdot 13$ & 440.99 & 152.96 & $625.59^{d}$ & $200 \cdot 56$ \\
\hline Ghrelin ( $n$ 15) & 5811.88 & 2244.33 & 7413.59 & $2012 \cdot 31$ & 7277.03 & 2524.58 & 9704.93 & $2536 \cdot 30$ \\
\hline
\end{tabular}

LP, low protein; LPP, low protein with polydextrose; HP, high protein; HPP, high protein with polydextrose.

a,b,c,d Mean values within a row with unlike superscript letters were significantly different $(P<0.05)$.

plasma insulin concentrations following the consumption of LP, LPP, HP and HPP preloads, nor was there an interaction of time and type of preload $(P>0 \cdot 05)$.

\section{Appetite hormones}

Plasma GLP-1 response increased and remained elevated until 90 min following the LPP, HP and HPP preloads. The plasma GLP-1 response elicited by the LP preload remained low for the initial $45 \mathrm{~min}$ and reached the peak value at $90 \mathrm{~min}$. Preloading with polydextrose and HP (LPP, HP and HPP) stimulated an increase in overall IAUC GLP-1. However, it was not statistically significant compared with LP. The HPP preload produced greater GLP-1 response compared with the LPP preload $(P<0.05)$ (Table 5), but no difference was observed when compared with LP. The HPP preload treatment produced the greatest IAUC, followed by HP, LPP and LP preload treatments. The consumption of LPP, HP and HPP preloads led to a 29, 68 and $138 \%$ augmentation in plasma GLP-1 response compared with the LP preload (Fig. 3(A)).

The greatest plasma ghrelin response was observed $15 \mathrm{~min}$ after the consumption of the preloads; thereafter, it decreased progressively and remained below the baseline. The LP preload treatment reached nadir at $60 \mathrm{~min}$, whereas the LPP, HP and
HPP preload treatments reached nadir at 90 min. Plasma ghrelin was suppressed far more by the HPP than the LP preload at 30 min $(P<0.05)$ (Fig. 3(B)). Plasma ghrelin was more suppressed by both HPP and LPP compared with the LP preload at 90 min $(P<0.05)$. The HPP preload treatment produced the greatest suppression of ghrelin, followed by the HP, LPP and LP preloads. The consumption of LPP, HP and HPP preloads led to a 28, 25 and $67 \%$ suppression, respectively, in plasma ghrelin response compared with the LP preload.

\section{Discussion}

This is the first study to demonstrate a significant reduction in short-term food intake using isoenergetic preloads, containing soya protein at two concentrations with/without polydextrose, in a Chinese population. Our present findings are in line with the literature that EI at a subsequent meal significantly decreased by $7-10 \%$ when a preload containing approximately $12 \mathrm{~g}$ polydextrose (Litesse $^{\circledR}$ ) was consumed ${ }^{(8,10)}$; this is the first study that has incorporated polydextrose within a soyabean curd matrix. Similarly, the consumption of LPP preload resulted in an energy reduction of $11 \%$ compared with the LP preload. Following all four preload treatments, subjective VAS 
(A)

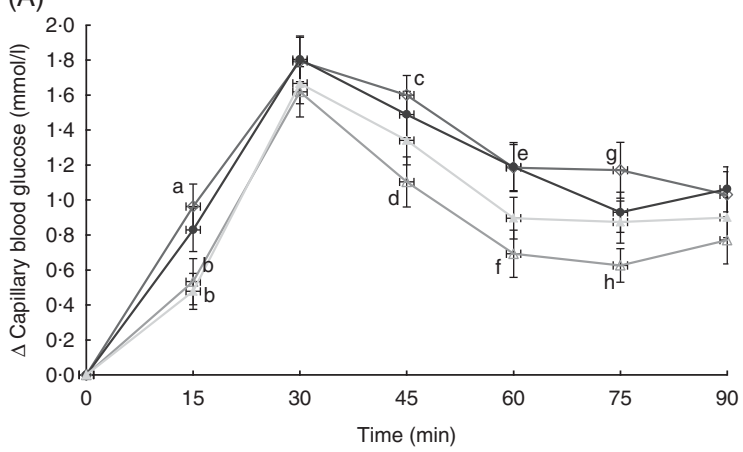

(B)

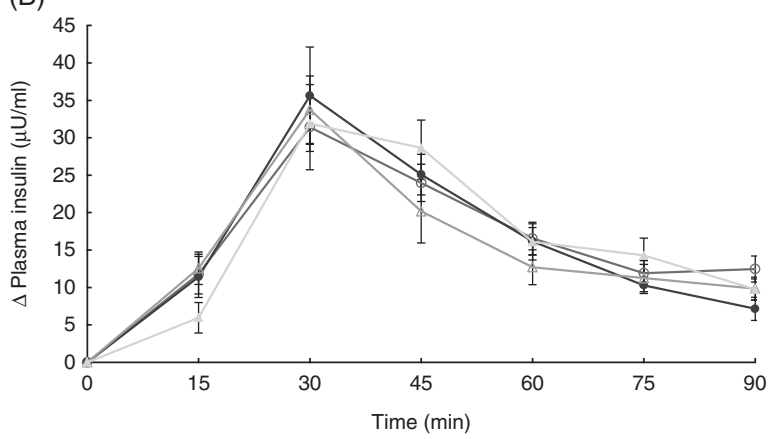

Fig. 2. Responses of (A) capillary blood glucose; (B) plasma insulin across different time points after consumption of soya protein and polydextrose preloads. Values are means, with their standard errors represented by vertical bars. ${ }^{\mathrm{a}, \mathrm{b}, \mathrm{c}, \mathrm{d}, \mathrm{e}, \mathrm{f}, \mathrm{g}, \mathrm{h}}$ Mean values at the same time point with unlike superscript letters were significantly different $(P<0.05) . \triangleleft$, Low protein; $\multimap-$, low protein with polydextrose; $\triangle$, high protein; $\longrightarrow$, high protein with polydextrose.

motivational ratings for hunger, fullness, desire to eat and prospective food consumption did not accurately predict the actual food intake as evident from the previous studies ${ }^{(9,20)}$.

The mechanistic effect of polydextrose on satiety is not fully understood. It has been postulated that the addition of polydextrose increases viscosity of the gastrointestinal contents, and thereby augments gastric distension and slows down gastric emptying $^{(7,21)}$. Production of SCFA through colonic fermentation of undigested polydextrose could activate the ileal brake and inhibit gastric emptying, leading to prolonged gastric distension $^{(22)}$. SCFA could also trigger secretion of GLP- ${ }^{(23)}$. Although there is no difference between LP and LPP in gastric distension, there were differences in HP and HPP compared with LP. The GER was reduced significantly following the consumption of LPP, HP and HPP preloads compared with the LP preload. Evidently, the polydextrose-induced EI suppression could be in part related to the distended stomach and delayed gastric emptying. The suppression effect of HPP preload on short-term EI was on par with LPP and HP preloads. Co-ingestion of protein and polydextrose in the LPP and HPP preloads curbed EI far more than the LP preload. However, the HPP preload did not further reduce the EI, attributed to the presence of higher protein content. From a mechanistic perspective, the reduced EI may be accounted for by the correspondingly greater ghrelin suppression at $90 \mathrm{~min}$ after ingestion of LP and HP preloads containing polydextrose.
(A)

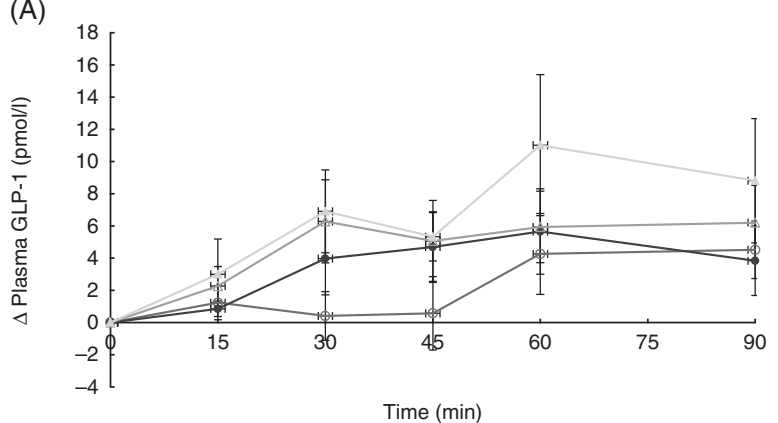

(B)

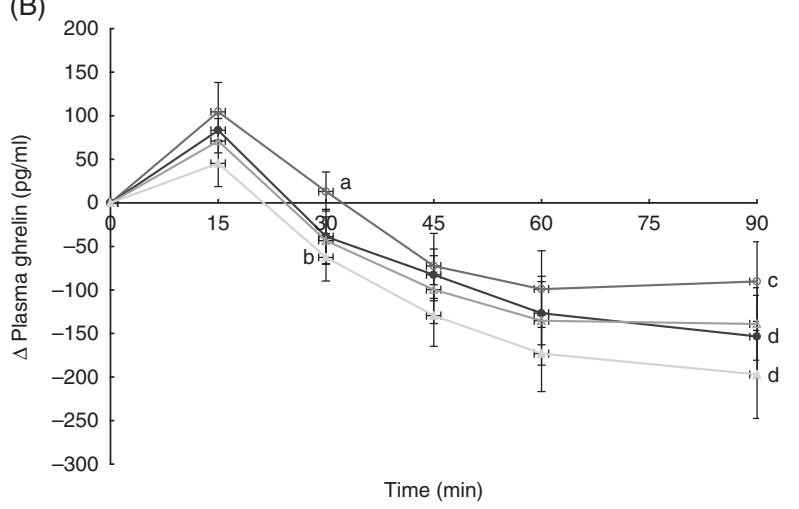

Fig. 3. Responses of (A) plasma glucagon-like peptide-1 (GLP-1) and (B) plasma ghrelin across different time points after consumption of soya protein and polydextrose preloads. Values are means, with their standard errors represented by vertical bars. ${ }^{a, b, c, d}$ Mean values at the same time point with unlike superscript letters were significantly different $(P<0.05)$. $\smile$, Low protein; $\longrightarrow$, low protein with polydextrose; $\_\triangle$, high protein; $-\triangle$, high protein with polydextrose.

This hormone response coincides with the observed reduction in EI following the consumption of the LPP and HPP preloads.

Protein is known to be more satiating than the isoenergetic ingestion of carbohydrates or fat ${ }^{(24)}$. Dose-responsive effects of soya protein on enhancing short-term satiety have been shown for the first time in this study, in Chinese populations. The present study demonstrated a $12 \%$ reduction of EI at a subsequent meal served $90 \mathrm{~min}$ after a HP preload compared with a LP preload. Given that GER was reduced significantly following HP preload consumption compared with LP preload, the protein-induced EI suppression observed in this study could be related in part to delayed gastric emptying.

Protein-induced satiety may also be triggered by anorexigenic gut hormones (i.e. GLP-1) or a decrease in orexigenic hormones (e.g. ghrelin). In the present study, there is a trend towards a higher GLP-1 response in preload containing HP compared with LP. Ghrelin response declined more following the consumption of LPP and HPP preloads compared to the LP preload. GLP-1 has been reported to slow gastric emptying of meals ${ }^{(25,26)}$. GER is positively associated with postprandial ghrelin responses but inversely associated with GLP-1 responses $^{(26,27)}$. The gastric emptying, gastric distension, glucose and insulin responses were similar between HP and HPP preloads, but the latter triggered a stronger GLP-1 response and ghrelin suppression. Following consumption of the LPP preload, GLP-1 responses increased by $29 \%$ compared with the LP preload. 
Slower GER could also allow for a prolonged period of stimulating the L-cells, and thus a prolonged period of elevated GLP-1. In addition, the increase in L-cells might result in increased vagal signalling, and this effect may thus not be mediated by changes in plasma concentrations, therefore reducing EI.

Dietary protein is known to be insulinotropic. Yet insulin concentrations did not significantly increase following the consumption of the HP preload. This observation confirmed the previous finding that vegetable protein (e.g. soya) induces lesser insulin secretion than animal protein (e.g. casein) ${ }^{(28)}$. No difference was detected in glycaemic and insulin responses between LP and LPP preloads. As the glucose concentration did not return to baseline and was still modestly elevated at $90 \mathrm{~min}$, this duration could be too short to observe any difference in postprandial GR compared with $150 \mathrm{~min}$ in a previous study ${ }^{(7)}$.

Limitations of the present study are that thirst and subjective symptoms of bloating, nausea, etc., were not measured. As our study showed that hormonal parameters (GLP-1, ghrelin) produced a positive response to appetite control, it is not known whether subjective symptoms of bloating may have also contributed to the reduced EI.

Among the macronutrients, protein has repeatedly been shown to have the greatest satiety power compared with carbohydrates and fats. The present study has demonstrated that the combination of soya protein and polydextrose in soyabean curd significantly impacts on food intake. More importantly, the study has revealed a synergistic effect on food intake when LP soyabean curd is combined with polydextrose. The main novelty of our study is that it has identified soyabean curd, a commonly consumed product among Chinese, as a vehicle for the inclusion of polydextrose. This combination has been shown to be able to reduce food intake significantly without changing its palatability and acceptability. Given the wide popularity and consumption of soyabean curd among Chinese, our study can serve as a guideline for developing functional foods for weight reduction and weight maintenance.

\section{Acknowledgements}

The authors thank Xin Yan Bi and Joseph Zhi'en Lim for analytical and technical support.

This study was funded by Agency for Science, Technology and Research (A*STAR) Industry Alignment Fund (IAF) from 20112014. This is not an industry-sponsored project, and A*STAR had no role in the design, conduct, analysis or writing of this article.

The authors' contributions are as follow: C. J. H., M. K. S. L. and Y. Y .S. contributed to the conception and the design of the study. Y. Y. S., W. X. L. and P. C. S. carried out the study and analysis of the samples. A. L. T. and P. C. S. were responsible for the statistical analysis. Y. Y. S., M. K. S. L., C. J. H. and P. C. S. drafted the manuscript. All the authors critically reviewed the contents of the manuscript and approved the final manuscript.

The authors declare that there are no conflicts of interest.

\section{References}

1. Garcia MC, Torre M, Marina ML, et al. (1997) Composition and characterization of soyabean and related products. Crit Rev Food Sci Nutr 37, 361-391.
2. Wayler A, Queiroz E, Scrimshaw NS, et al. (1983) Nitrogen balance studies in young men to assess the protein quality of an isolated soy protein in relation to meat proteins. J Nutr $\mathbf{1 1 3}$, 2485-2491.

3. Hall WL, Millward DJ, Long SJ, et al. (2003) Casein and whey exert different effects on plasma amino acid profiles, gastrointestinal hormone secretion and appetite. Br J Nutr $\mathbf{8 9}$, 239-248.

4. Pal S \& Ellis V (2010) The acute effects of four protein meals on insulin, glucose, appetite and energy intake in lean men. Br J Nutr 104, 1241-1248.

5. Anderson GH, Tecimer SN, Shah D, et al. (2004) Protein source, quantity, and time of consumption determine the effect of proteins on short-term food intake in young men. J Nutr 134, 3011-3015.

6. Auerbach MH, Craig SAS, Howlett JF, et al. (2007) Caloric availability of polydextrose. Nutr Rev $\mathbf{6 5}, 544-549$.

7. Jie Z, Bang-Yao L, Ming-Jie X, et al. (2000) Studies on the effects of polydextrose intake on physiologic functions in Chinese people. Am J Clin Nutr 72, 1503-1509.

8. Hull S, Re R, Tiihonen K, et al. (2012) Consuming polydextrose in a mid-morning snack increases acute satiety measurements and reduces subsequent energy intake at lunch in healthy human subjects. Appetite 59, 706-712.

9. King NA, Craig SA, Pepper T, et al. (2005) Evaluation of the independent and combined effects of xylitol and polydextrose consumed as a snack on hunger and energy intake over $10 \mathrm{~d}$. Br J Nutr 93, 911-915.

10. Ranawana V, Muller A \& Henry CJK (2013) Polydextrose: its impact on short-term food intake and subjective feelings of satiety in males - a randomized controlled cross-over study. Eur J Nutr 52, 885-893.

11. Monsivais P, Carter BE, Christiansen M, et al. (2011) Soluble fiber dextrin enhances the satiating power of beverages. Appetite 56, 9-14.

12. Willis HJ, Eldridge AL, Beiseigel J, et al. (2009) Greater satiety response with resistant starch and corn bran in human subjects. Nutr Res 29, 100-105.

13. Venn B, Williams S \& Mann J (2010) Comparison of postprandial glycaemia in Asians and Caucasians. Diabet Med 27, 1205-1208.

14. Baecke J, Burema J \& Frijters J (1982) A short questionnaire for the measurement of habitual physical activity in epidemiological studies. Am J Clin Nutr 36, 936-942.

15. Mullin W, Fregeau-Reid J, Butler M, et al. (2001) An interlaboratory test of a procedure to assess soybean quality for soymilk and tofu production. Food Res Int 34, 669-677.

16. Darwiche G, Almér L-O, Björgell O, et al. (1999) Measurement of gastric emptying by standardized real-time ultrasonography in healthy subjects and diabetic patients. J Ultrasound Med 18, 673-682.

17. Darwiche G, Björgell O, Thorsson O, et al. (2003) Correlation between simultaneous scintigraphic and ultrasonographic measurement of gastric emptying in patients with type 1 diabetes mellitus. J Ultrasound Med 22, 459-466.

18. Hveem K, Jones K, Chatterton B, et al. (1996) Scintigraphic measurement of gastric emptying and ultrasonographic assessment of antral area: relation to appetite. Gut 38, 816-821.

19. Flood MT, Auerbach MH \& Craig SAS (2004) A review of the clinical toleration studies of polydextrose in food. Food Chem Toxicol 42, 1531-1542.

20. Stubbs RJ, Hughes DA, Johnstone AM, et al. (2000) The use of visual analogue scales to assess motivation to eat in human subjects: a review of their reliability and validity with an evaluation of new hand-held computerized systems for temporal tracking of appetite ratings. Br J Nutr 84, 405-415. 
21. Holt S, Carter D, Tothill P, et al. (1979) Effect of gel fibre on gastric emptying and absorption of glucose and paracetamol. Lancet 313, 636-639.

22. Powley TL \& Phillips RJ (2004) Gastric satiation is volumetric, intestinal satiation is nutritive. Physiol Behav 82, 69-74.

23. Tolhurst G, Heffron H, Lam YS, et al. (2012) Short-chain fatty acids stimulate glucagon-like peptide-1 secretion via the G-protein-coupled receptor FFAR2. Diabetes 61, 364-371.

24. Westerterp-Plantenga M, Rolland V, Wilson S, et al. (1999) Satiety related to $24 \mathrm{~h}$ diet-induced thermogenesis during high protein/carbohydrate vs high fat diets measured in a respiration chamber. Eur J Clin Nutr 53, 495-502.
25. Nauck MA, Niedereichholz U, Ettler R, et al. (1997) Glucagonlike peptide 1 inhibition of gastric emptying outweighs its insulinotropic effects in healthy humans. Am J Physiol 273, E981-E988.

26. Näslund E, Gutniak M, Skogar S, et al. (1998) Glucagon-like peptide 1 increases the period of postprandial satiety and slows gastric emptying in obese men. Am J Clin Nutr 68, 525-530.

27. de la Cour CD, Lindström E, Norlén P, et al. (2004) Ghrelin stimulates gastric emptying but is without effect on acid secretion and gastric endocrine cells. Regul Pept 120, 23-32.

28. Ascencio C, Torres N, Isoard-Acosta F, et al. (2004) Soy protein affects serum insulin and hepatic SREBP-1 mRNA and reduces fatty liver in rats. $J$ Nutr $\mathbf{1 3 4}, 522-529$. 